\title{
ASSESSING THE IMPACTS OF FLOODING CAUSED BY EXTREME RAINFALL EVENTS THROUGH A COMBINED GEOSPATIAL AND NUMERICAL MODELING APPROACH
}

\author{
J. R. Santillan ${ }^{\mathrm{a} *}$, A. M. Amora ${ }^{\mathrm{a}}$, M. Makinano-Santillan ${ }^{\mathrm{a}, \mathrm{b}}$, J. T. Marqueso ${ }^{\mathrm{a}}$, L. C. Cutamora ${ }^{\mathrm{a}}$, J. L. Serviano ${ }^{\mathrm{a}}$, R. M. Makinano ${ }^{\mathrm{a}}$ \\ ${ }^{a}$ CSU Phil-LiDAR 1 Project, Caraga Center for Geo-Informatics, College of Engineering and Information Technology, \\ Caraga State University, Ampayon, Butuan City, Agusan del Norte, Philippines - jrsantillan@ carsu.edu.ph \\ ${ }^{\mathrm{b}}$ Division of Geodetic Engineering, College of Engineering and Information Technology,Caraga State University, \\ Ampayon, Butuan City, Agusan del Norte, Philippines - mmsantillan@ carsu.edu.ph
}

KEY WORDS: Extreme rainfall, Flooding, Impact assessment, 2D Flood modeling, LiDAR, Landsat

\begin{abstract}
:
In this paper, we present a combined geospatial and two dimensional (2D) flood modeling approach to assess the impacts of flooding due to extreme rainfall events. We developed and implemented this approach to the Tago River Basin in the province of Surigao del Sur in Mindanao, Philippines, an area which suffered great damage due to flooding caused by Tropical Storms Lingling and Jangmi in the year 2014. The geospatial component of the approach involves extraction of several layers of information such as detailed topography/terrain, man-made features (buildings, roads, bridges) from 1-m spatial resolution LiDAR Digital Surface and Terrain Models (DTM/DSMs), and recent land-cover from Landsat 7 ETM+ and Landsat 8 OLI images. We then used these layers as inputs in developing a Hydrologic Engineering Center Hydrologic Modeling System (HEC HMS)-based hydrologic model, and a hydraulic model based on the 2D module of the latest version of HEC River Analysis System (RAS) to dynamically simulate and map the depth and extent of flooding due to extreme rainfall events. The extreme rainfall events used in the simulation represent 6 hypothetical rainfall events with return periods of 2, 5, 10, 25, 50, and 100 years. For each event, maximum flood depth maps were generated from the simulations, and these maps were further transformed into hazard maps by categorizing the flood depth into low, medium and high hazard levels. Using both the flood hazard maps and the layers of information extracted from remotely-sensed datasets in spatial overlay analysis, we were then able to estimate and assess the impacts of these flooding events to buildings, roads, bridges and landcover. Results of the assessments revealed increase in number of buildings, roads and bridges; and increase in areas of land-cover exposed to various flood hazards as rainfall events become more extreme. The wealth of information generated from the flood impact assessment using the approach can be very useful to the local government units and the concerned communities within Tago River Basin as an aid in determining in an advance manner all those infrastructures (buildings, roads and bridges) and land-cover that can be affected by different extreme rainfall event flood scenarios.
\end{abstract}

\section{INTRODUCTION}

\subsection{Background}

Flooding is one of the most destructive natural disasters in the Philippines. Excessive quantity of rainfall brought by tropical storms is the most common cause of flooding, just like what happened in various provinces in Mindanao Island when Tropical Storms Lingling (Local name: Agaton) and Jangmi (Local name: Seniang) caused rivers and lakes to overflow in 2014 (NDRRMC, 2014; 2015). In the advent of climate change which has caused tropical storms and the rains that it brings along becoming fiercer and extreme, the need to become more prepared for flood disasters has also become more urgent (Few, 2003; Vidal and Carrington, 2013). It is in this need that simulating and assessing the impacts of various flood scenarios is important not only for the purpose of establishing a baseline information where disaster managers can make a reference to when doing pre- and postdisaster management and recovery efforts, but also for getting a detailed picture of how and why such kind of flooding can occur or have occurred. These assessments are vital in figuring out strategies that can minimize, or even avoid, the impacts should similar events occur in the future. Flood impact assessment can also help communities and local government units to be empowered in finding ways to mitigate the negative impacts of flooding,

\footnotetext{
${ }^{*}$ Corresponding author
}

as well as in evaluating adaptation strategies if such kind of flooding will actually occur in the near future (Few, 2003).

\subsection{Flood Risk Assessment}

Assessing the risk of present and future flooding, especially those brought by extreme rainfall events, is a very challenging task, especially that the components of flood risk, such as the exposures and hazards are subject to fast changes in time due to economic development and the possible effect of the changing climate (Alfieri et al., 2015). In many studies (e.g. Alfieri et al., 2015; Gilbuena et al., 2013; Ortiz et al., 2016), deriving potential damages caused by flooding includes combining and intersecting flood hazard maps with the exposed population and land cover features. These methods are done with the use of Remote Sensing (RS) and Geographic Information System (GIS) techniques, which has significantly improved the efficiency of flood disaster monitoring and management (Haq et al., 2012; Van Westen, 2013). Utilizing these technologies, a quicker and precise monitoring and mapping of flooding can be done by using satellite images and state-of-the-art modelling or simulation software (Haldar and Khosa, 2015; Haq et al., 2012).

In the last few decades, numerical modeling has been significantly enhanced and utilized in flood mapping due to the existence of reliable numerical methods and innovative topographic survey techniques such as those provided by Light Detection and Ranging or LiDAR technology (Costabile and Macchione, 
2015). Typically, flood mapping through numerical simulations comprises two components known as the hydrological simulation which quantifies the size, duration and probability of the flood event; and the hydraulic simulation which employs the mapping of inundated areas (Dimitriadis, et al., 2016). Flood mapping can be done in either 1-dimensional (1D) or 2-dimensional (2D) approach, but despite the efficiency if 1D flood modeling approach, it has been progressively encouraged recently the use of 2D flood simulation, since it can give detailed description of the hydraulic behaviour of the river's flow dynamics (Costabile and Macchione, 2015).

\subsection{The case of Tago River Basin in Mindanao, Philippines}

Tago River Basin (Figure 1) is located in the province of Surigao del Sur in the island of Mindanao, Philippines. It is geographically facing the Pacific region wherein typhoons usually come from. The basin's large catchment area of approximately 1,444 $\mathrm{km}^{2}$ and a very wide floodplain traversed by a dense network of rivers and streams make it vulnerable to flooding. Flooding in the river basin due to overflowing of Tago River and its tributaries occurs almost every year, especially during the rainy seasons from the month of December to February. In 2014, the basin was one of the many areas greatly affected by flooding due to heavy to torrential rains brought about by the passing of tropical storms $\mathrm{Aga}$ ton and Seniang (NDRRMC, 2014; 2015). These flood events affected not only the communities living in the flood plain but also the sources of income which include large cropland areas.

A preliminary assessment of the impacts of Agaton and Seniang in the Tago River Basin has recently been conducted by Makinano-Santillan (2015). Using an integrated approach involving the use of LiDAR datasets, land-cover from Landsat images, and one-dimensional (1D) flood models based on HEC HMS and HEC RAS, the study was able to estimate $52.57 \%$ and $22.29 \%$ of the buildings situated in the floodplains to have been flooded during the two flood events, respectively. Cropland areas were also found to be the most affected based on the model simulations and geospatial analysis. However, the results of the study was hindered by the low accuracy $(70.30 \%)$ of the flood models to predict flood depth and extents which may have been caused by the limitations in the input data as well as in the 1D modelling approach used. The input data limitation was on the use of LiDAR Digital Terrain Model (DTM) without bathymetry data. Since the flood model did not account the actual river bed topography, the river flow dynamics were not fully characterized, and may have falsely predicted flood depth and extent. On the other hand, the low accuracy of the 1D hydraulic model (based on HEC RAS) maybe due to the model's discretization of topography as cross sections rather than as a surface, including the subjectivity of cross-section location and orientation as well as its inability to simulate lateral diffusion of the flood wave (Samuels, 1990; Hunter et al., 2007). With 2D flood modeling, these fundamental constraints can be overcome (Hunter et al., 2007).

\subsection{Objectives of the Study}

In this paper, we present a combined geospatial and numerical modeling approach to assess the impacts of flooding due extreme rainfall events by fully utilizing the benefits of high spatial resolution topographic and feature information provided by LiDAR technology, land-cover information from Landsat images, and 2D flood models. Focusing on the Tago River Basin as our case study area, we apply this approach to estimate how hypothetical extreme rainfall events with return periods of 2, 5, 10, 25, 50 and 100 -years can bring flooding, and how it can impact buildings, roads, bridges and land-cover.

\section{METHODS AND MATERIALS}

\subsection{The Combined Geospatial and 2D-Numerical Modeling Approach}

Figure 2 summarizes the combined geospatial and numerical modeling approach as implemented in this study for flood impact assessment.

The geospatial component of the approach involves extraction of exposure datasets from remotely-sensed high spatial resolution elevation models and images. These exposure datasets are the man-made features (buildings, roads, bridges) and land-cover which are extracted through manual digitization and image classification, respectively. The numerical modeling consisted of developing the hydrologic model of the river basin which is then used to determine the volume and discharge of water entering the floodplains; and the 2D hydraulic model which simulates the flow of water entering on the rivers and on the floodplains as rain pours to the area. The development of the hydrologic and hydraulic models utilizes high spatial resolution elevation models and were parameterized using the information extracted from the land-cover map. The models simulate flooding events by inputting rainfall data which can either be actual or hypothetical rainfall events.

2D numerical modeling is very advantageous compared to $1 \mathrm{D}$ modeling especially when dealing with a complicated river system that has multiple streams with complex flows. 2D modeling also removes subjective techniques usually employed in developing a 1D model, such as cross-section orientation.

The 2D hydraulic model uses flow information computed by the hydrologic model to generate flood maps corresponding to hypothetical rainfall events with return periods of 2, 5, 10, 25, 50 and 100 years. The flood depth and extent generated are then categorized based on the different flood hazard levels. The categorization are low hazard for depths of less than $0.50 \mathrm{~m}$, medium hazard for depths from $0.50 \mathrm{~m}$ to $1.50 \mathrm{~m}$, and high hazard for depths of greater than $1.50 \mathrm{~m}$. These maps are then utilized together with the extracted exposure datasets in the spatial overlay analysis to assess the various levels of impacts of flooding brought by 6 different extreme rainfall events.

\subsection{Exposure Dataset Extraction}

2.2.1 Feature Extraction: One of the basic inputs for flood impact assessment is a hazard exposure dataset. The exposure datasets considered in this study are the man-made features (buildings, roads, bridges) and the land-cover within the floodplains of Tago River Basin. The man-made exposure datasets were manually digitized from 1-m spatial resolution LiDARderived DTM and DSM acquired last 2014 by the University of the Philippines - Diliman Disaster Risk and Exposure Assessment for Mitigation (UP DREAM) Program. The extraction process was aided with the use of high-resolution satellite images from Google Earth.

2.2.2 Land-cover Map Derivation: The land-cover information of Tago River Basin was obtained though Maximum Likelihood (ML) classification of Landsat 8 OLI and Land 7 ETM+ satellite images which were downloaded from the USGS Earth Explorer (http://earthexplorer.usgs.gov/). More than one image was utilized for Tago River Basin image classification. This was done to supplement missing data in one image caused by the presence of cloud-cover. The images used are the Landsat 8 OLI images acquired last March 31 and June 3, 2014, and Landsat 7 

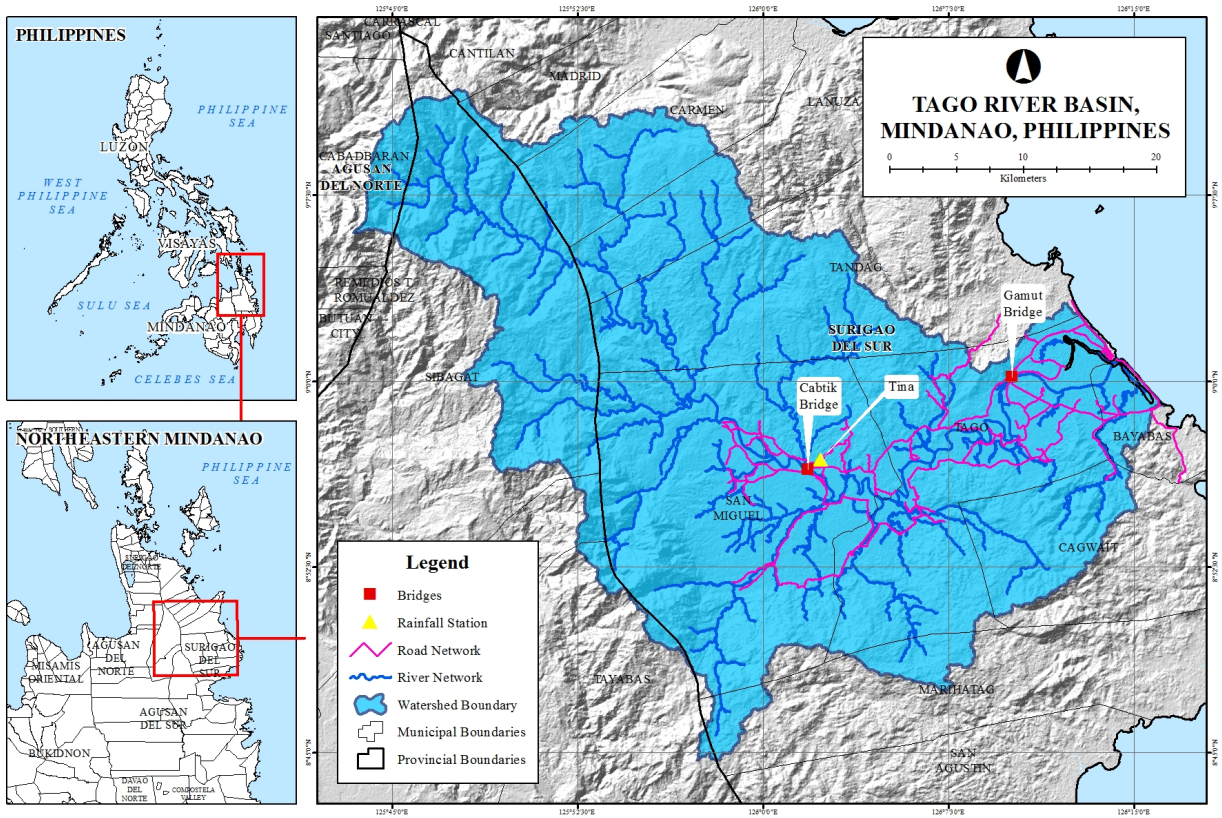

Figure 1: Map showing the location and coverage of Tago River Basin.

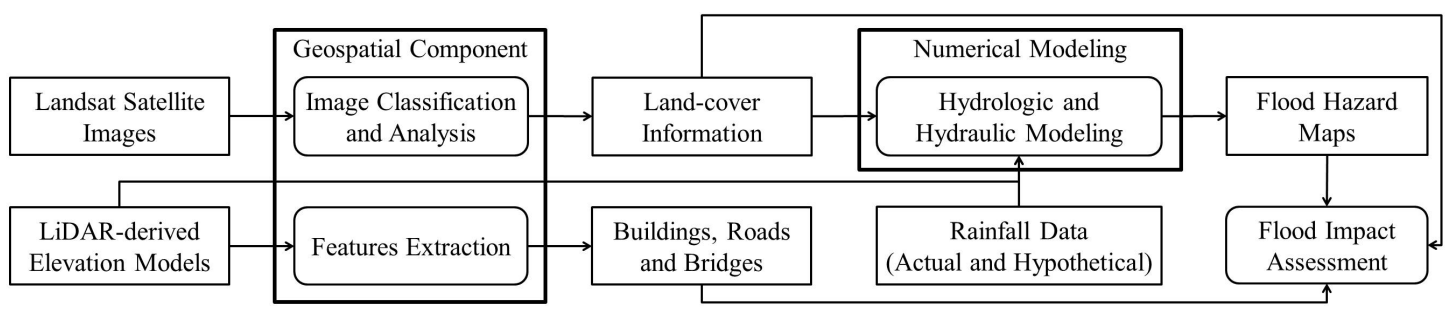

Figure 2: A combined geospatial and 2D numerical modeling approach for flood impact assessment.

ETM+ image acquired last August 8, 2012. These images underwent pre-processing including radiometric calibration which converts image pixel values to top-of-atmosphere (TOA) radiance; and atmospheric correction which corrects the pixel values for atmosphere effects and to convert the TOA radiance to surface reflectance. NDVI and DEM were also incorporated to the Landsat surface reflectance bands as additional data sources for land-cover classification since it has been found to increase classification accuracy. NDVI and DEM can account for the rugged topography so as to eliminate the presence or absence of certain classes in some elevation zones, and reduces the impact of shadows and to enhance the separation among various land-cover classes (Watanachaturaporn et al., 2008). There were seven classes considered in the analysis: barren, built-up, cropland, grassland, palm, forest, and water areas. The March 2014 image served as the main image for classification. The missing land-cover information due to the presence of cloud and cloud shadow in this image was supplemented using the land-cover maps derived from individual ML classification of the June 2014 and August 2012 images. After supplementing the missing data in the land-cover map, it was further subjected to contextual editing to correct obvious misclassification through visual inspection.

The accuracy of the finalized land-cover map was then assessed using a procedure suggested by Congalton and Green (2009). The procedure involves a random selection of at least 50 points (or validation pixels) for each land-cover class in the finalized landcover map. The actual land-cover classes of these random points were then verified by overlaying them to high resolution satellite images available in Google Earth. The minimum of 50 points per class is considered a rule-of-thumb in assessing the accuracy of land-cover maps whose coverage is less than 1 million acres (approx. 40,469 $\mathrm{km}^{2}$ ) in size and with fewer than 12 land-cover classes (Congalton and Green, 1999). For Tago River Basin, the area covered is only $1,444 \mathrm{~km}^{2}$. Hence, only 50 random points per class were selected. With 8 land-cover classes, there were a total of 400 random points. The comparisons between the actual and classified land-cover classes for each random point were then summarized using a confusion or error matrix. From this matrix, the Overall Classification Accuracy, Producers Accuracy and Users Accuracy were then computed.

The land-cover map was used to obtain land-cover statistics of the basin. It was also converted into runoff potential (or Curve Number, $\mathrm{CN}$ ) and Mannings roughness maps which are required parameters in the development of the hydrologic and 2D hydraulic models.

\subsection{Numerical Modeling and Flood Hazard Maps Genera- tion}

2.3.1 Hydrologic Model Development and Calibration: The hydrologic model of Tago River Basin was developed using the Hydrologic Engineering Center Hydrologic Modeling System (HEC HMS) Version 3.5, a software specifically designed to simulate the precipitation-runoff processes of watershed systems (USACE, 2000). HEC HMS modeling is dependent on three components: the basin model, meteorological model, and a set of 
control specification indicating the time step and simulation period. The basin model, which is the physical representation of the watershed, was developed by utilizing a 10-m Synthetic Aperture Radar Digital Elevation Model (SAR DEM) and the rivers networks in the delineation of watersheds; and was parameterized using the information from the land-cover map that was generated earlier.

The hydrologic model can simulate actual and historical rainfall events by using the rainfall data recorded by the Advanced Science and Technology Institute of the Department of Science and Technology (ASTI DOST) rain gauge located at Barangay Tina in the Municipality of San Miguel (Figure 1); and hypothetical rainfall events by using the Rainfall Intensity Duration Frequensy (RIDF) data from the Philippine Atmospheric, Geophysical and Astronomical Services Administration (PAGASA). RIDF curves provide information on the likelihood of rainfall events of various amounts and durations. For this study, we used RIDF of the Hinatuan PAGASA Weather Station which is nearest to the basin. These extreme rainfall events are expressed as "return period". For every rain return period, a 24-hour duration rainfall scenario was constructed in HEC HMS wherein the rain was set to peak at the sixth hour from the start of the simulation (see Figure 3 and Table 1).

Prior to its use in simulating flow hydrographs due to extreme rainfall events, the parameters of the model were calibrated by relating the simulated flow hydrographs to the actual measured flow in the river. The station utilized during model calibration was Cabtik Bridge. Hydrological data necessary for calibration was gathered from this station last 12/16/2014 to 12/23/2014 with the use of water level and velocity data logging sensors together with the river cross-section data. In evaluating the model performance before and after calibration, three measures of accuracy were used. These are the Nash-Sutcliffe Coefficient of Model Efficiency (NSE), percentage bias (PBIAS), and the RMSE - observations standard deviation ratio (RSR). These measures were computed by comparing the observed and the simulated hydrographs in accordance with existing evaluation guidelines for systematic quantification of accuracy in hydrological simulations (Moriasi et al., 2007).

2.3.2 Hydraulic Model Development: The 2D hydraulic model of Tago River Basin was based on the Hydrologic Engineering Center River Analysis System (HEC RAS) version 5.0, which is designed to perform one-dimensional (1D), twodimensional (2D), or combined 1D and 2D hydraulic calculations for a full network of natural and constructed channels (USACE, 2016). For Tago River Basin, 2D modeling was performed with no $1 \mathrm{D}$ element present. The 2D HEC RAS model was developed by creating a $2 \mathrm{D}$ flow area (i.e., the $2 \mathrm{D}$ model domain) representing the entire floodplain of the river basin. The $2 \mathrm{D}$ flow area mesh of Tago has an approximate area of $565.31 \mathrm{~km}^{2}$ and was computed using a $60-\mathrm{m}$ by $60-\mathrm{m}$ cell size. This cell size was chosen since Tago River Basin has a very large $2 \mathrm{D}$ area and setting it with a much smaller cell size would make run times of the simulations much longer. With the aid of break lines representing the roads, dikes, levees and river banks, the $2 \mathrm{D}$ flow area was finally computed to consist a total of 162,565 cells. The 1 -m spatial resolution LiDAR-derived DTM and the Manning's roughness coefficients extracted from the land-cover map were used as inputs in setting the model's geometric data. The model consisted of 10 boundary conditions in which 8 are inflows from upstream rivers, 1 as the tidal boundary condition at the sea, and 1 boundary condition for the precipitation that falls to the $2 \mathrm{D}$ area

2.3.3 Flood Depth and Hazard Mapping: The flow hydrographs generated by the calibrated HEC HMS model were used as inputs into the HEC RAS 2D hydraulic model to predict or estimate flood depths and extents. Each hydrograph represents the flow of water entering the 2D model domain, i.e., at the 8 inflow boundary condition locations. These flow hydrographs together with the time series of rainfall and tidal data were utilized by the unsteady flow analysis module of HEC RAS to dynamically simulate depth and extent of flooding. For each extreme rainfall event flood simulation, a spatially-distributed grid of maximum flood depths was generated. This depth grid was then exported as a raster file in the GIS software ArcGIS and converted into flood hazards by categorizing depths to its corresponding hazard levels (low: $<0.50 \mathrm{~m}$ depth, medium: $0.50 \mathrm{~m}-1.50 \mathrm{~m}$ depth, and high: $>1.50 \mathrm{~m}$ depth).

Before using the combined HEC HMS-HEC RAS 2D in generating flood hazard maps, its accuracy was first determined. Using the 2 models, a flooding in the area that happened last January 2014 caused by tropical storm Agaton was reconstructed. The combined models utilized actual rainfall data recorded from the ASTI-DOST rainfall station at barangay Tina, San Miguel. The resulting flood map from this flooding reconstruction was then compared to the actual flooding information gathered in the field. Flood map validation surveys were conducted to gather this information last February 2015. Pre-determined random locations within the floodplain of Tago River Basin were visited to determine whether they were flooded or not during Agaton. The accuracy computation includes the use of confusion matrix approach which was done by comparing the total number of correctly predicted points over the total number of points collected; and the measure of fit known as F Measure which answers the question of whether the flood extent reflected in the map is the same on the ground (Aronica, et al., 2002; Horritt, 2006). The computation was done using the formula:

$$
F=\frac{A}{A+B+C}
$$

where $F=$ the measure of fit; $A=$ the number of points correctly predicted as "flooded'; $B=$ the number of over-predicted points ("not flooded" in reality but predicted as "flooded"); and $C$ $=$ the number of under-predicted points ("flooded" in reality but predicted as "not flooded"). $F=1$ means that the observed and predicted flooding extents coincide exactly, while $F=0$ means that no overlap exists between predicted and observed flooding extents. Flooding extents generated by the model can be assessed either as Good Fit ( $F$ is greater than or equal to 0.7 ), Intermediate Fit ( $F$ is from 0.5 to less than 0.7), or Bad Fit ( $F$ less than 0.5) (Breilh, et al., 2013).

\begin{tabular}{|l|c|c|c|c|c|c|}
\hline \multirow{2}{*}{ Duration } & \multicolumn{7}{|c|}{ Return Period (Years) } \\
\cline { 2 - 7 } & 2 & 5 & 10 & 25 & 50 & 100 \\
\hline $5 \mathrm{~min}$ & 12.1 & 15.9 & 18.5 & 21.7 & 24.1 & 26.4 \\
\hline $15 \mathrm{~min}$ & 27.2 & 35.9 & 41.7 & 49.0 & 54.4 & 59.8 \\
\hline $1 \mathrm{hr}$ & 61.8 & 82.8 & 96.6 & 114.2 & 127.2 & 140.1 \\
\hline $2 \mathrm{hrs}$ & 85.8 & 116.9 & 137.5 & 163.5 & 182.8 & 202.0 \\
\hline $3 \mathrm{hrs}$ & 103.8 & 141.9 & 167.2 & 199.1 & 222.8 & 246.3 \\
\hline $6 \mathrm{hrs}$ & 132.7 & 190.6 & 228.9 & 277.3 & 313.2 & 348.8 \\
\hline $12 \mathrm{hrs}$ & 164.3 & 230.6 & 274.4 & 329.8 & 370.9 & 411.7 \\
\hline $24 \mathrm{hrs}$ & 201.0 & 276.5 & 326.5 & 389.7 & 436.6 & 483.1 \\
\hline
\end{tabular}

Table 1: The extreme values (in $\mathrm{mm}$ ) of precipitation of the 6 hypothetical rainfall events based on RIDF data of Hinatuan PAGASA Weather Station.

\subsection{Flood Impact Assessment}

The impacts of flooding were assessed through spatial overlaying of the exposure datasets (building, roads, bridges and land- 


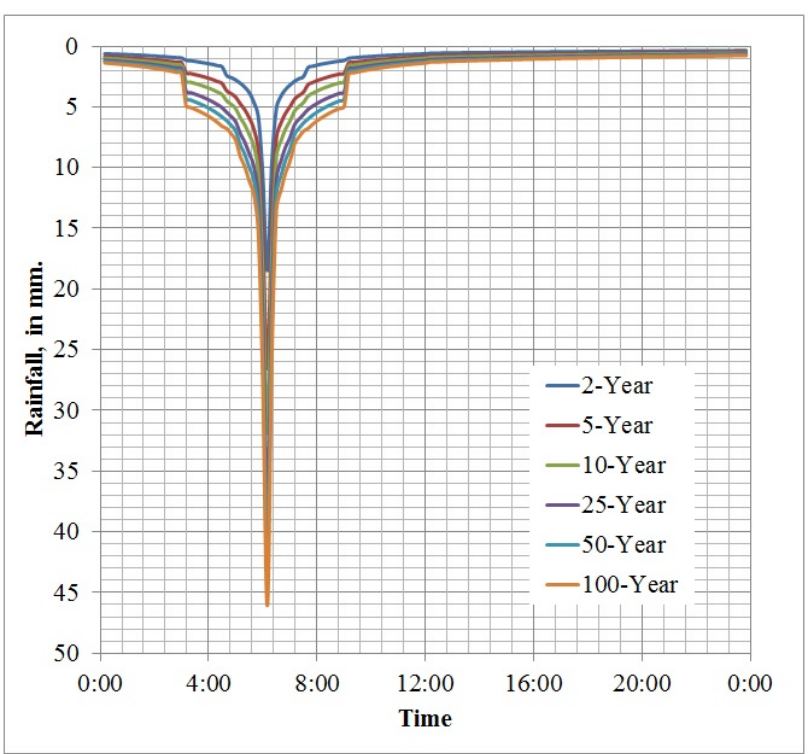

Figure 3: 24-hour rainfall scenario for the 6 hypothetical extreme rainfall events.

cover) with the generated flood hazard maps for the different rainfall events using ArcGIS software. The flooding impact to landcover classes was determined by computing the inundated areas for each class for all events. For buildings and roads, flooding impacts were assessed by categorizing every building and road according to hazard level (low, medium, high, or not flooded) depending on what hazard level they are intersected with. The impacts of flooding to bridges were assessed by comparing their elevation to the maximum elevation of flood water where there are located; this will determine whether a certain bridge will already be un-passable if a flooding due to a particular extreme rainfall event will occur.

\section{RESULTS AND DISCUSSION}

\subsection{Exposure Datasets}

3.1.1 Buildings, Roads and Bridges: The digitized exposure datasets derived using the 1-m spatial resolution LiDARderived DSM of Tago River Basin floodplain areas totaled to 12,830 buildings, 228 roads and 69 bridges. These features were checked and validated using the high-resolution satellite images from Google Earth.

3.1.2 Land-cover: The land-cover map of Tago River Basin derived from the analysis of the Landsat satellite images is shown in Figure 4 with its statistics listed in Table 2. This land-cover map has an over-all classification accuracy of $92 \%$, with the Producer's and User's Accuracies for all land-cover classes greater than $85 \%$. It can be found that next to forest, cropland is the major land-cover in the river basin, occupying $11.65 \%$ of the basin's total land area.

\subsection{Accuracy of the Hydrologic Model}

Figure 5 shows the results after the calibration of the Tago HEC HMS model. Based on Moriasi et al. (2007)'s evaluation guidelines, the overall performance of the model was found to be very good, with an NSE $=0.98$, PBIAS $=-0.76$, and RSR $=0.15$. This means that the HEC HMS can be confidently used in simulating flow hydrographs for extreme rainfall event scenarios.

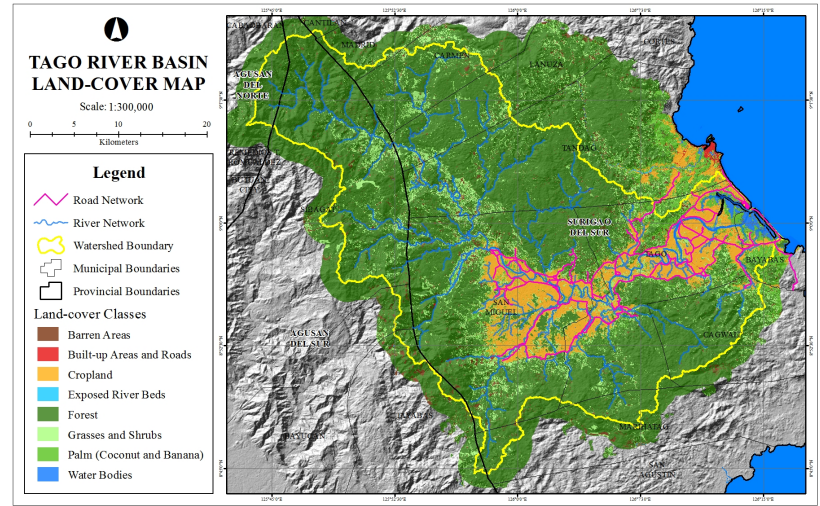

Figure 4: The year 2014 land-cover map of Tago River Basin derived from Landsat images.

\begin{tabular}{|l|c|}
\hline Class Name & Area, in $^{2} \mathrm{~km}^{2}$ \\
\hline Barren Areas & 51.14 \\
\hline Built-ups and Roads & 4.39 \\
\hline Cropland & 168.35 \\
\hline Forest & 999.12 \\
\hline Grasses and Shrubs & 146.43 \\
\hline Palm (Coconut and Banana) & 55.30 \\
\hline Water Bodies & 19.75 \\
\hline Total & $1,444.49$ \\
\hline
\end{tabular}

Table 2: Area per land-cover class in Tago river basin

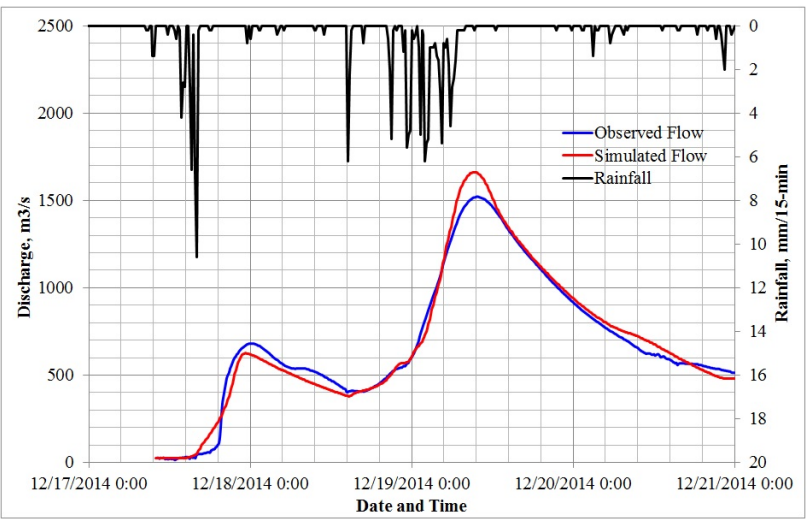

Figure 5: Result of calibrating the Tago HEC HMS model using the measured flow data at Cabtik Bridge.

\subsection{Flood Hazard Maps Generated using Combined HMS and RAS Models and Its Accuracy}

Example flow hydrographs simulated by the calibrated HEC HMS model at Cabtik Bridge station for the different extreme rainfall events are shown in Figure 6. It can be seen that as the rainfall return period increases (i.e., as rainfall becomes extreme), the peak flow rate in Cabtik Bridge also increases from approximately $2,500 \mathrm{~m}^{3} / \mathrm{s}$ for a 2 -year return period to more than 8,000 $\mathrm{m}^{3} / \mathrm{s}$ for a 100 -year return period rainfall event.

The generated flood hazard maps of Tago River Basin for the 6 extreme rainfall events are shown in Figure 7. It can be found that as the rainfall return period increases, the extent of flooding also increases.

The accuracy of these flood hazard maps can be approximated using the results of the validation of the Agaton flood map gen- 

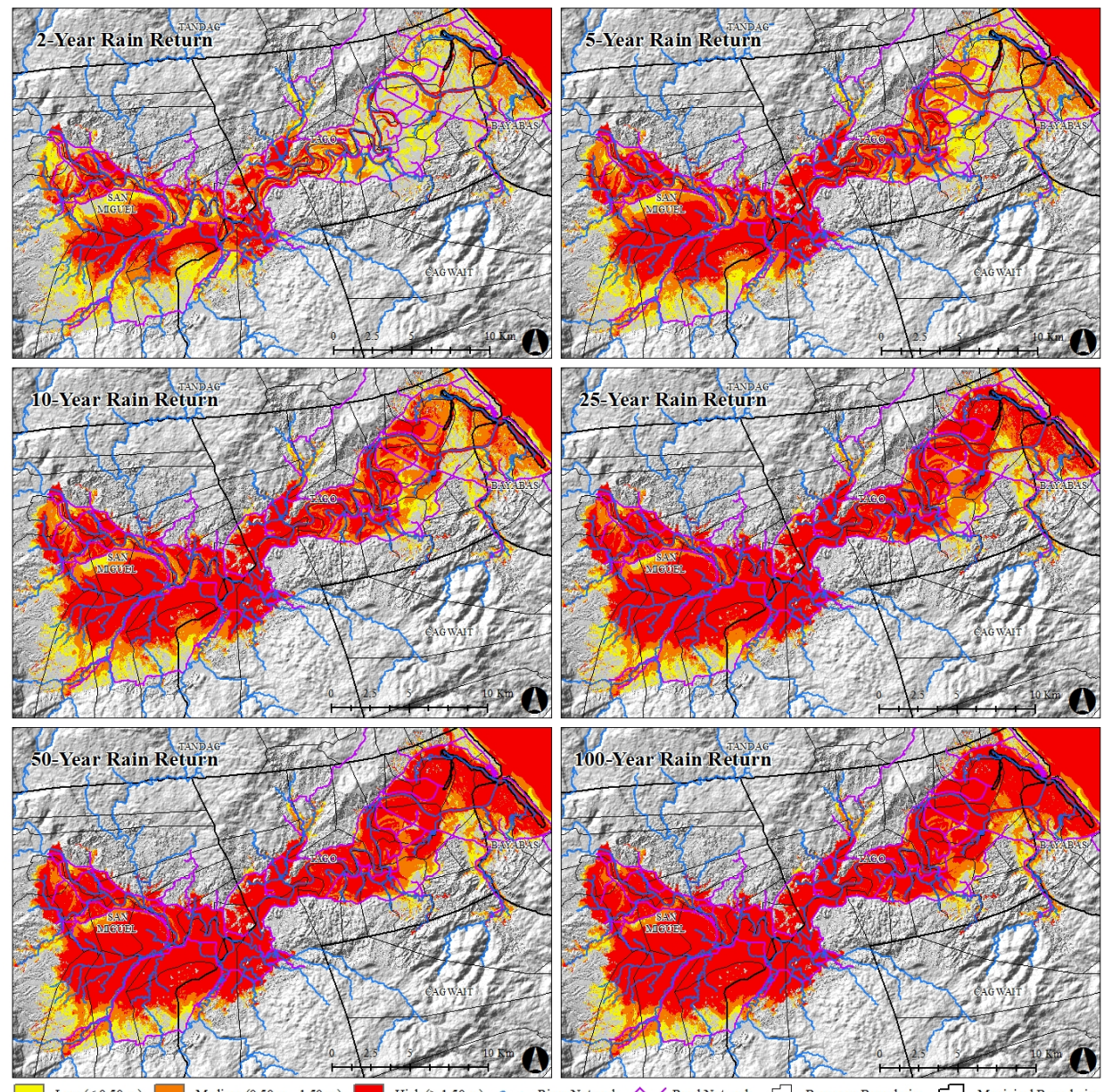

Figure 7: The generated flood hazard maps of Tago River Basin for the 6 rainfall return periods.

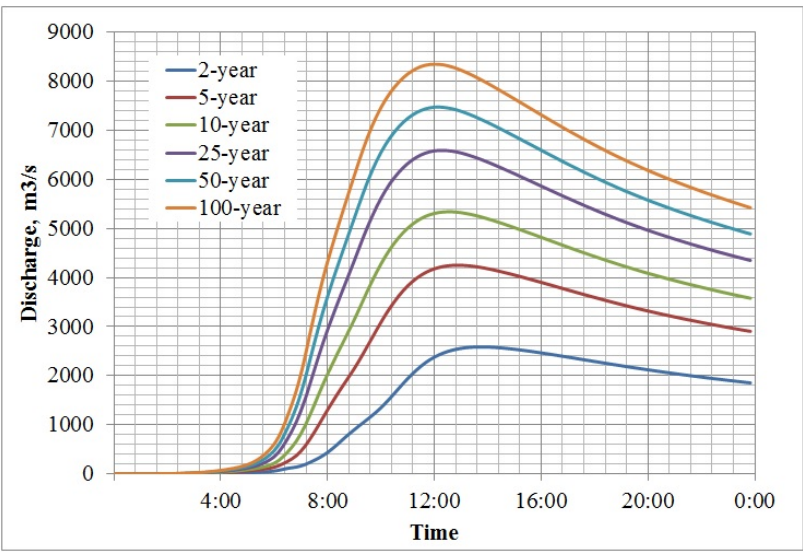

Figure 6: 24-hour outflow hydrographs generated at Cabtik Bridge station for the 6 rain return periods.

erated by the same models (Figure 8). Utilizing the flood information gathered within Tago River Basin floodplain areas the reconstructed flooding extent during tropical storm Agaton was analyzed. The $F$ Measure was calculated as 0.81 , indicating that the flood map generated by the combined HEC HMS-HEC RAS 2D models is a good fit. The accuracy of the model, based on the result of the confusion matrix analysis (Table 3), is $83.33 \%$, which leads us to an assumption that any flooding event the models generates is approximately $83.33 \%$ accurate.

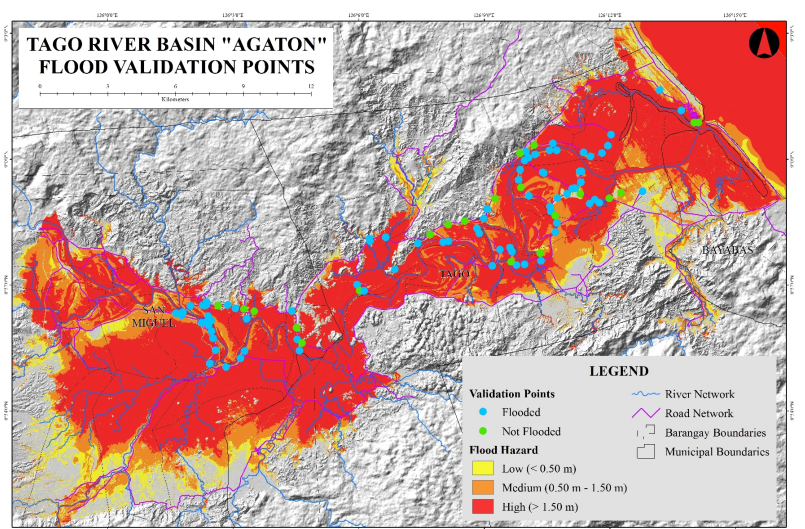

Figure 8: Map showing the validation points in Tago River Basin overlaid in the generated Agaton flood hazard map.

\subsection{Flood Impact Assessment}

The results of assessing the impacts of flooding to the buildings, roads, bridges and land-cover in Tago River Basin floodplain areas are shown in Figure 9, Figure 10 Figure 11 and Figure 12, respectively.

It was found that the area of inundated land-cover and the number of affected buildings, roads and bridges increase as the rainfall event return period increases. Among the land-cover classes, the 


\begin{tabular}{|c|c|c|c|c|c|}
\hline & \multicolumn{3}{|c|}{ Actual Flooding Scenario } & \multirow{2}{*}{$\begin{array}{l}\text { User's } \\
\text { Accuracy }\end{array}$} \\
\hline & & Flooded & $\begin{array}{c}\text { Not } \\
\text { Flooded }\end{array}$ & Total & \\
\hline \multirow{3}{*}{$\begin{array}{c}\text { Flood } \\
\text { Model } \\
\text { Simulated } \\
\text { Flooding }\end{array}$} & Flooded & 74 & 11 & 85 & $87.06 \%$ \\
\hline & $\begin{array}{c}\text { Not } \\
\text { Flooded }\end{array}$ & 6 & 11 & 17 & $64.71 \%$ \\
\hline & Total & 80 & 22 & 102 & \\
\hline \multicolumn{2}{|c|}{ Producer's Accuracy } & $92.50 \%$ & $50.00 \%$ & & \\
\hline \multicolumn{2}{|c|}{$\begin{array}{c}\text { Sum of Diagonal } \\
\text { Values }\end{array}$} & \multicolumn{2}{|c|}{85} & & \\
\hline \multicolumn{2}{|c|}{ Overall Accuracy } & \multicolumn{2}{|c|}{$83.33 \%(85 / 102)$} & & \\
\hline
\end{tabular}

Table 3: Result of the flood map accuracy analysis in Tago River Basin for the Agaton event.

cropland areas are the most affected with $66.27 \%$ and $90.70 \%$ inundated for a 2-year and 100-year rainfall return periods, respectively. For the flooding impact assessment on the buildings exposure datasets, it can be noted that several structures are flooded even for just a 2-year rainfall return. A total of 6,662 out of 12,830 buildings or $51.93 \%$ will be flooded for a 2-year rain return event that is having a $50 \%$ probability of occurrence every year. For the worst case scenario, a 100 -year rain return event is expected to inundate 10,674 or $83.20 \%$ buildings, 204 or $89.47 \%$ roads, and 33 or $47.83 \%$ bridges. All of these results are assumed to be $83.33 \%$ accurate based on the result of the flood map validation.

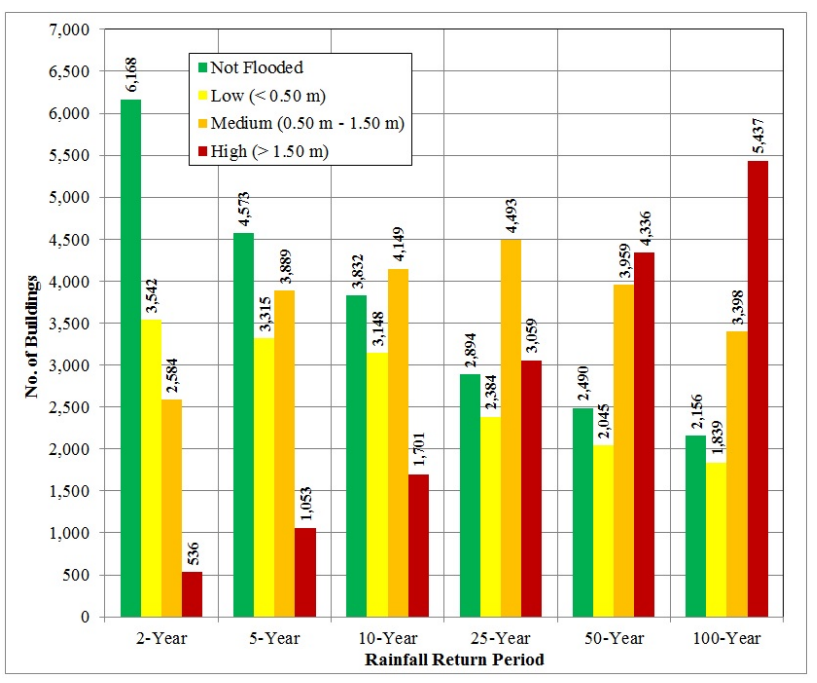

Figure 9: Number of affected buildings for each of the 6 extreme rainfall events.

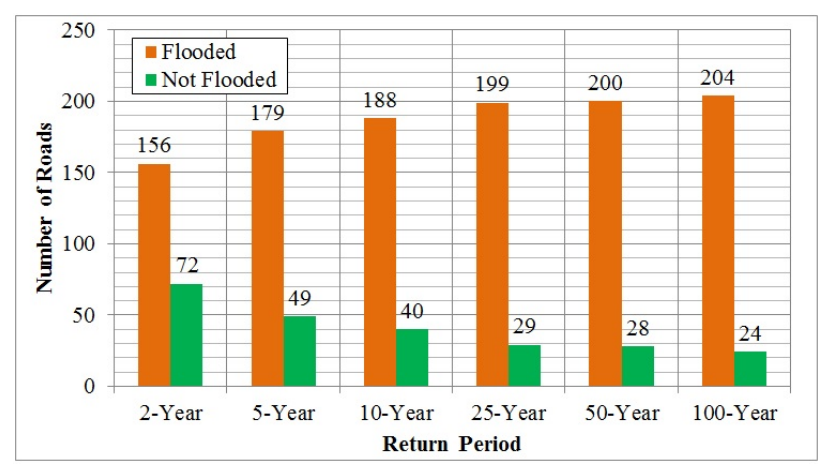

Figure 10: Number of affected roads for each of the 6 extreme rainfall events.

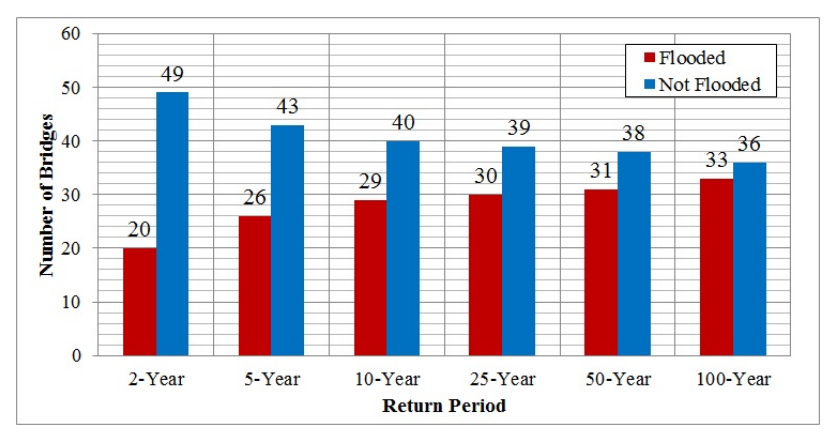

Figure 11: Number of flooded bridges for each of the 6 extreme rainfall events.

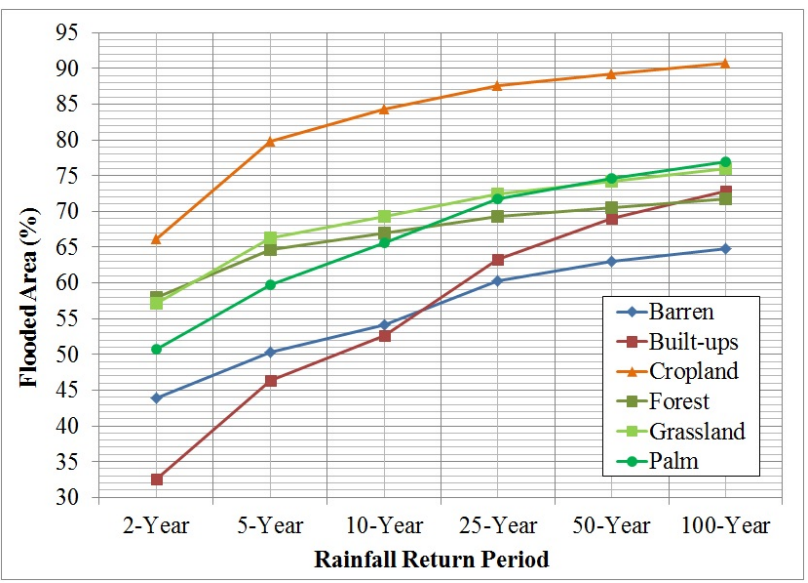

Figure 12: Percentage of flooded land-cover class for each of the 6 extreme rainfall events.

\section{CONCLUSION}

A detailed assessment of flooding was presented with the use of the combined geospatial and numerical modeling approach. This approach was found to be very useful in assessing flooding impacts of extreme rainfall events to the features at risk within the floodplains of Tago river basin. With the utilization of high spatial resolution digital elevation models, Landsat satellite images and flood models, detailed information on the possible affected buildings, roads, bridges and land-cover was determined. The results of the assessments ashowed an increase in the number of buildings and roads, and increase in areas of inundated land-cover as rainfall events become more extreme (i.e., increase in return periods). The results of these assessments can be considered more reliable than the assessment conducted earlier (Makinano-Santillan et al., 2015) due to higher accuracy of the flood maps generated in the present study.

The wealth of information generated from the flood impact assessment using the approach can be very useful to the local government units (LGUs) and the concerned communities within Tago River Basin as an aid in determining in an advance manner all those infrastructures (buildings, roads and bridges) and land-cover that can be affected by different extreme rainfall event flood scenarios. These assessments are very timely especially that rains brought by storms have become fiercer in recent years, and will continue to be so due to the effect of climate change. With the knowledge learned from the numerical model simulations and flood hazard mapping, LGUs and the communities in Tago River Basin can be informed and empowered in finding ways to mitigate the negative impacts of flooding, as well as in 
evaluating adaptation strategies if more intense events will occur in the near future. These adaptation strategies may include (i.) localized land-use planning integrating flood hazard information, (ii.) relocating communities to safe grounds, (iii.) identification and improvement of evacuation routes, and (iv.) building flood defences (specifically in areas where river overflowing occurs), among many others.

\section{ACKNOWLEDGEMENTS}

This work is an output of the Caraga State University (CSU) PhilLiDAR 1 project under the Phil-LiDAR 1. Hazard Mapping of the Philippines using LiDAR program funded by the Department of Science and Technology (DOST). The SAR DEM and the LiDAR DTM and DSM including the river bathymetric data used in this work were provided by the University of the Philippines Disaster Risk and Exposure for Mitigation (UP DREAM)/PhilLIDAR 1 Program. We thank all CSU-Phil-LIDAR 1 technical staff and assistants, as well as the Local Government Units in the Tago River Basin for their assistance during the conduct of hydrological measurements and flood map validation surveys.

\section{REFERENCES}

Alfieri, L., Feyen, L., Dottori F., Bianchi A., 2015. Ensemble flood risk assessment in Europe under high end climate scenarios. Global Environmental Change, 35, pp. 199-212.

Aronica, G., Bates, P. D., and Horritt, M. S., 2002. Assessing the uncertainty in distributed model predictions using observed binary pattern information within GLUE. Hydrological Processes, 16(10), pp. 2001-2016.

Breilh, J. F., Chaumillon, E., Bertin, X., Gravelle, M., 2013. Assessment of static flood modeling techniques: application to contrasting marshes flooded during Xynthia (western France). Natural Hazards and Earth System Science, 13(6), 1595-1612.

Congalton, R.G., Green, K., 2009. Assessing the Accuracy of Remotely Sensed Data: Principles and Practices Second Edition, CRC Press/Taylor and Francis, Boca Raton, Florida, USA.

Costabile P., Macchione F., 2015. Enhancing river model set-up for 2-D dynamic flood modelling. Environmental Modelling and Software, 67, pp. 89-107.

Dimitriadis P., Tegos A., Oikonomou A., Pagana V., Koukouvinos A., Mamassis N., Koutsoyiannis D., Efstratiadis A., 2016. Comparative evaluation of 1D and quasi-2D hydraulic models based on benchmark and real-world applications for uncertainty assessment in flood mapping. Journal of Hydrology, 534, pp.478492.

Few R., 2003. Flooding, vulnerability and coping strategies: local response to a global threat. Progress in Development Studies, 3(1), pp. 43-58.

Gilbuena Jr. R., Kawamura A., Medina, R., Nakagawa, N., Amaguchi H., 2013. Environmental impact assessment using a utility-based recursive evidential reasoning approach for structural flood mitigation measures in Metro Manila, Philippines. Journal of Environmental Management, 131, pp. 92-102.

Haldar, R., Khosa R., 2015. Flood level mitigation study using 1-D hydrodynamic modeling. Aquatic Procedia, 4, pp. 925-932.
Haq M., Akhtar M., Muhammed S., Paras S., Rahmatullah J., 2012. Techniques of remote sensing and GIS for flood monitoring and damage assessment: A case study of Sindh province, Pakistan. The Egyptian Journal of Remote Sensing and Space Science, 15(2), pp. 135-141.

Horritt, M. S., 2006. A methodology for the validation of uncertain flood inundation models. Journal of Hydrology, 326, 153165 .

Hunter, N.M., Bates, P.D., Horrit, M.S., Wilson, M.D., 2007. Simple spatially-distributed models for predicting flood inundation: A review. Geomorphology, 90, pp. 208-225.

Makinano-Santillan, M., Santillan, J.R, Amora, A.M., Marqueso, J.T., Cutamota L.C., Serviano J.L., Oconer P.C.R., Makinano R.M., 2015. Assessing the impacts of flooding in Tago River Basin, Mindanao, Philippines through integration of high resolution elevation datasets, Landsat image analysis, and numerical modelling. In: 36th Asian Conference on Remote Sensing 2015 (ACRS 2015): Fostering Resilient Growth in Asia, Quezon City, Metro Manila, Philippines, Vol. 3, pp. 1606-1617.

Moriasi, D.N., Arnold, J.G., Van Liew, M.W., Bingner, R.L., Harmel, R.D., Veith, T.L., 2007. Model evaluation guidelines for systematic quantification of accuracy in watershed simulations. Transactions of the ASABE, 50, pp. 885-900.

NDRRMC, 2014. NDRRMC Updates Sitrep No. 33 re: Effects of Tropical Depression Agaton. National Disaster Risk Reduction and Management Council. http://www.ndrrmc.gov.ph/ (01 February 2014).

NDRRMC, 2015. NDRRMC Updates Sitrep No. 22 re: Effects of Tropical Storm Seniang. National Disaster Risk Reduction and Management Council. http://www.ndrrmc.gov.ph/ (22 January 2015).

Ortiz R., Ortiz P., Martin J. M., Vazquez, M. A., 2016. A new approach to the assessment of flooding and dampness hazards in cultural heritage, applied to the historic centre of Seville (Spain). Science of the Total Environment, 551-552, pp. 546-555.

Samuels, P.G., 1990. Cross-section location in 1-D models. In: White, W.R., Watts, J. (Eds.), 2nd International Conference on River Flood Hydraulics, Wiley, Chichester, pp. 339350.

USACE, 2000. Hydrologic Modeling System HEC-HMS Technical Reference Manual, United States Army Corps of Engineers, Hydrologic Engineering Center, Davis, California, USA.

USACE, 2016. HEC-RAS River Analysis System Hydraulic Reference Manual, Institute for Water Resources Hydrologic Engineering Center, Davis, California, USA.

Van Westen, C. J., 2014. Remote sensing and GIS for natural hazards assessment and disaster risk management. Reference Module in Earth Systems and Environmental Sciences, pp. 259-298.

Vidal J., Carrington, D., 2013. Is climate change to blame for Typhoom Haiyan?.Guardian News and Media. http://www.theguardian

.com/world/2013/nov/12/typhoon-haiyan-climate-changeblame-philippines.html (14 Januaryl 2016).

Watanachaturaporn, P., Arora, M.K., Varshney, P.K., 2008. Multisource classification using support vector machines: an empirical comparison with decision tree and neural network classifiers. Photogrammetric Engineering and Remote Sensing, 74, pp. 239246. 